City University of New York (CUNY)

CUNY Academic Works

\title{
Watching and Talking About AIDS: Analog Tapes, Digital Cultures and Strategies for Connection
}

Alexandra Juhasz

CUNY Brooklyn College

Theodore Kerr

The New School

\section{How does access to this work benefit you? Let us know!}

More information about this work at: https://academicworks.cuny.edu/bc_pubs/270

Discover additional works at: https://academicworks.cuny.edu

This work is made publicly available by the City University of New York (CUNY).

Contact: AcademicWorks@cuny.edu 


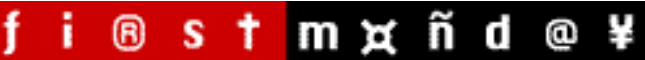

PEER-REVIEWED JOURNAL ON THE INTERNET

\section{Watching and talking about AIDS:}

Analog tapes, digital cultures, and

strategies for connection

by Alexandra Juhasz and Theodore Kerr

\begin{abstract}
This paper is a conversation between activist videomaker Alexandra Juhasz and writer and organizer Theodore (ted) Kerr that explores the contemporary role of AIDS activist videos from the past.. Key to the text are ideas around history, technology, time, and community. Together they discuss and enact intergenerational dialogue, what to do with the imperfection of archives, and strategies for shared looking at the history of HIV through epochs. Their conversation is focused on a community created tape from, Bebashi - Transition to Hope, a Philadelphia non-profit.
\end{abstract}

\section{Contents}

$\underline{\text { Introduction }}$

Interview

Watching AIDS in time

Final decision

Humane salvaging

Grandma's legacy

What is a trigger tape?

Trigger 


\section{Introduction}

The following is a conversation between activist videomaker and scholar Alexandra Juhasz and writer and organizer Theodore (ted) Kerr that explores the contemporary role of AIDS activist videos from the past. Key to their connection are ideas circulating and building around history, technology, time, and community. Together they discuss and enact intergenerational dialogue, what to do with the imperfection of archives, and strategies for shared looking at the history of HIV through epochs. Their conversation stays focused on a community-created tape from the late 1980s made by the Philadelphia non-profit, Bebashi - Transition to Hope. This conversation began as they watched the video, newly digitized as a DVD, in Alex's Brooklyn living room. Their back and forth bloomed and unfurled over time, shared breakfasts, e-mails, a Google doc or two, long walks, and multiple reviewings of the tape, both alone and together.

As a writing process Ted will craft a first draft, after the pair have discussed in person, and then Alex will follow. This is what they did for this essay, and how they wrote most of their book, We Are Having this Conversation Now: The Times of AIDS Cultural Production (forthcoming, Duke University Press), of which their interactions about the Bebashi tape play a significant part. Then, together - buoyed, inspired, confused, or confronted by what the other was expressing or perhaps missing - they respond on Google docs over the course of a few weeks, until a final draft is refined. As needed, the pair discusses what is taking shape as writing online by talking over the phone, or in person on what became fondly known as "bagel walks" in their neighborhood (given that Ted couldn't come in to Alex's apartment anymore because of Alex's child's cat!), gaining nourishment, fresh air, and clarity regarding structure and content as they walked.

We have tried to honor the moods of these off-line encounters in our written conversation - specifically the moments of care and also those of tension - so that the complexity and even difficulty of our connection can be registered. As final activities, before inviting others into the editing process like our two peer reviewers for this effort, Jih-Fei Cheng and Shaka McGlotten, Alex goes through the text cleaning up errors (Ted is a terrible speller!), while Ted adds images (he's great at that ...). Then together they discuss titles, captions, footnotes, and finally, readers' responses. Now, we share this with you, one of several instantiations of and invitations to join us or others in conversation about the times of AIDS. You can take account of your own feelings and ideas as you are reading along with us. Or, at the end of this text, you can follow our prompts and begin your own conversations about the tape, or its many related issues, by commencing your own, with a friend, colleague, or honored interlocutor. 


\section{Interview}

Alexandra Juhasz (Alex): We see a tall Black woman with brown eyes and hair pulled back. She is on the phone with her arm in a sling. A young girl in a solid colored sweatshirt, the daughter we soon learn, plays with blocks on the floor. The two actors are surrounded by a set meant to convey home: a table with plates and cutlery, a couch and a room divider.

Theodore Kerr (Ted): We are watching a VHS video, which is an aesthetic I was born into, it warms up my senses, providing me with a strong feeling of familiarity, a location in terms of time and space.

Alex: Weird. Video feels so cold to me, dead as it must be. Sure it connects me to a time I remember, but one that was hard and cruel when I was living it, and then also hard and cruel now, in a different way, because as much as I might want, I have little access (beyond tapes) to this, which is also my young adulthood, my first time of AIDS. 


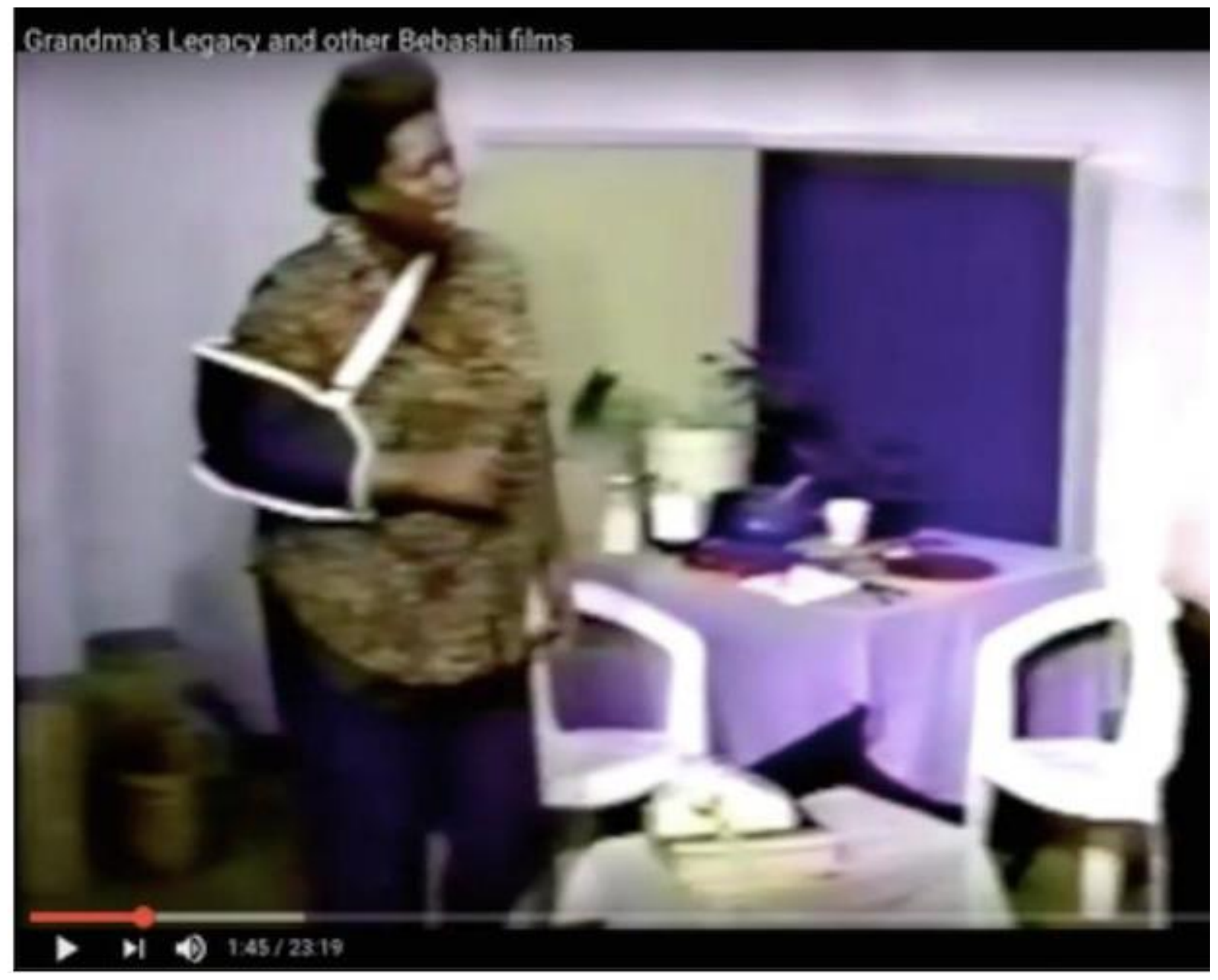

Figure 1: The first vignette concerns domestic violence.

Ted: As we continue to watch, it's not clear to me if there's a script or if they are improvising. "Girl, I'm about at the end of my rope," the woman proclaims dramatically into the phone. A wide shot follows where we see the child continuing to play in the background. The mother holds the receiver close to her face with one hand and clutches the phone cord with the other. She explains that she is stuck in an abusive relationship and looking for a chance to vent - as well as another place to stay, just in case. She is determined, strong, and holding her ground. There is a disruption as static rumbles deeper for a beat on the soundtrack. The woman reports, worried, that her man is coming home. She instructs her daughter to clean up her toys. 
Alex: We learn from her side of the phone call that her man did not return home last night and this causes her distress not only because she does not know where he had been but because of the disrespect his absence shows her in their relationship. $\mathrm{He}$ enters. Silent at first, he becomes quickly loud and menacing.

Ted: Things move forward in a bad way. His anger turns towards the child. The woman puts herself between her daughter and the man, collecting the girl and taking her quickly out of the room and off screen. When she returns, she attempts to mollify him. This scenario fades to black as she draws him into a vivid, heated, clothed, but highly sexual embrace. From the overheard phone call, we know she has a place she could go if she needs to leave. But we don't know if she ever gets there. The scene ends before her story does.

Alex: With this dip to black, the family and all its myriad tensions, uncertainties, and realms of possible danger vanishes from the screen. The video - a "trigger tape," a structure and method we will discuss in depth towards the end of this conversation was made to be stopped here, even as two more scenes are promised to follow.

\section{Watching AIDS in time}

Ted: In the late 1980s, precise date unknown, a cast of four unnamed and uncredited Black women, two Black men, and a Black child starred in three video vignettes produced by Bebashi, a still-operating although ever-changing Philadelphia based AIDS service organization formed in 1985. Watching it today, viewers have a chance to witness rarely shared and still under-considered stories about Black women's lives told through the lens of prevailing social issues - domestic abuse, drug use, economic dependence, parenting, poverty, sex work, and HIV/AIDS - written into three private dramas. The title of the first scenario, briefly outlined above, is currently a mystery as it was left blank on the copy we watched (a recently made DVD digitized from Alex's VHS tape which was itself a dub made of another VHS tape probably in the late 1980s). The second scenario is "Final Decision" (according to Alex's handwriting on the VHS label which we learned later during our "research" [1]), and the third, "Grandma's Legacy," both of which we will describe as the conversation continues.

Alex: Little is known today about the video or the project or people who created it [2]. What can be learned comes from the vignettes themselves; the DVD and its original video label which read "BEBASHI/AMFAR DUB"; as well as short observations I 
wrote when I first viewed the tape in the late 1980s or early 1990s as research for my doctoral dissertation on AIDS activist video [3] . At the time, I was writing about and contributing to a significant body of AIDS related representational work taking place in all art forms and across sectors. My dissertation was completed in 1991 and was adapted into AIDS TV: Identity, community, and alternative video (Durham, N.C.: Duke University Press, 1995), so I focused on video made from about 1987 to 1993. The Bebashi tape was one of a diverse, powerful, and life-saving body of work made by people living with HIV and other activists who were artists, scholars, critics, and community members. In our book, We are having this conversation now: The times of $A I D S$, we call this period of considerable cultural production, AIDS Crisis Culture, and recognize its central place in the history of AIDS.

Ted: This period is defined by both an abundance of representation, community, and resolve and a related disavowal, neglect, and even overt oppression from official quarters like the government, public health, families, mainstream media, or the church. Many works from AIDS Crisis Culture have gone on to re-circulate within Western media circles and art worlds, such as the output of Gran Fury, ACT UP, David Wojnarowicz or Keith Haring.

Alex: This, the period where I entered AIDS activism is closely related to our current period, one also defined by an outpouring of cultural production, albeit defined by historical reflection. This we dub the AIDS Crisis Revisitation, a period we see starting around 2008. During the Revisitation, the smaller, community-based efforts have proven harder to find or remember, especially those made by and for communities who were and continue to be mostly left out of mainstream AIDS narratives, such as the Black women and their communities and families featured in this one forgotten video. When these diligently told stories are not brought forward, we lose hard won knowledge as well as history. But we are convinced, and hope to show how the carefully documented techniques, tools, and analyses that communities used to survive, thrive, and in some cases die in dignity, can be (re) learned from these lesser-known works of highly impacted communities. We know this was useful in and for their time and AIDS activist communities, and we are certain of is value for ours today.

Ted: In thinking about why some work gets dragged forward, and some does not, it is hard to not consider the role that anti-Black racism, misogyny, and even homophobia play in what gets saved, shared, and remembered from our AIDS pasts.

Alex: And as we argue elsewhere [4], this is not simply a matter of identity or audience. Rather, it is about the infrastructures of history and historiography: who creates and accesses the archive; who has both the time and the desire to consider the 
past through material artifacts; what urgencies and desires are behind various impulses for an historic turn.

Ted: Our interest in and commitment to this work is to expand what and who can be remembered, given their stated interest in this being done ... .

Alex: ... so that more pasts and people and processes can be accessed for all of us impacted by AIDS. I want a world where people who care about these subjects are as well-versed in ACT UP focused works like United in Anger (Jim Hubbard, 2012) and BPM (Robin Campillo, 2017) as they are in the diverse AIDS cultural output of filmmakers and artists like James Wentzy (Native Americans, Two Spirits \& HIV, 1991; Fight Back, Fight AIDS: 15 Years of ACT UP, 2002), Tiona Nekkia McClodden (Bumming Cigarettes, 2012; The Labryinth, 2017) or Jean Carlomusto (Sex in an Epidemic, 2010; Larry Kramer in Love and Anger, 2015), all of whom - along with legions of others - have made, and continue to make, thought-provoking and elegiac work about HIV in the past and present [5].

Ted: Engaging in and with the past is never easy work and as I hope we are illustrating, it can't really be done alone. You need friends and peers. You need curiosity and questions.

Alex: You need comrades who will show you things you don't know and never saw.

Ted: And, as we suggest, having frameworks can also be helpful: ones that allow for openness, engagement, disagreement, and questioning with some promise of safety as feelings flow; others that provide structure and cohesion so that our ever-developing thoughts can enjoy some discipline.

Alex: In our work together, we have tried to create both kinds of frameworks. We think about, improve, and try to share our processes of conversation and interaction, between the two of us, within our community, and making best uses of salvaged and beloved objects.

Ted: So, as we have already started to introduce, we have chosen to break down the periods of AIDS cultural production into five times via a timeline of moments, that while readily identifiable, personally and culturally felt, are also surprisingly and usefully mutable.

1. Pre-1981: AIDS before AIDS The virus has been circulating within humans from as early as the 1900s in Cameroon, and as early as the late 1960s in the U.S. There are lived experiences of HIV well before 1981, but these occur outside of 
discourse. Even so, a then-unnamed illness impacts individuals and communities.

2. 1981-1987: The First Silence

In the early 1980s, medical staff and impacted people begin to take action around a mysterious health concern. Their work is done primarily in isolation. Coordinated efforts are blocked by the Reagan administration and an apathetic and uninformed media and public. The result: a once possibly manageable health crisis becomes an epidemic.

3. 1987-1996: AIDS Crisis Culture

From the "Silence = Death" poster to community-produced video and historic levels of direct action, this is a period of mass cultural production and discourse about HIV/AIDS leading to social, political, and medical breakthroughs.

4. 1996-2008: The Second Silence

The introduction of HAART (highly active antiretroviral therapy) produces better health for many and an associated decline in the space taken up by HIV in public. While HIV-related activity is ongoing it becomes, again, less connected and less visible.

5. 2008-Present: AIDS Crisis Revisitation A sudden deluge of cultural production focused on earlier responses to the virus breaks the silence. Cultural production returns to the stories, images, memories, and loss of the first generations. This is met with more: excitement, criticism, connection. A richer understanding of AIDS - whether that be in terms of race, gender, or sexuality, prevention, or undetectability - enters discourse.

Alex: And, because our work is in process, and AIDS is ongoing, I want to remind you that we've lately been considering what we are calling the 6th time: AIDS Inclusive Culture (2010-ongoing), where representations of AIDS move beyond neglect or spectacle. It seems like things are changing again and, at times, we have reached a point where the inclusion of AIDS within the national narrative can be and sometimes is respected and intersectional.

Ted: Right, this possible sixth time of AIDS can be seen connected to the AIDS Crisis Revisitation and AIDS Normalization. We write about this elsewhere including in our upcoming book, and the Summer 2020 issue of X-TRA Contemporary Art Quarterly.

Alex: I like this open part of our process. It gets to what we are trying to communicate. Our hope is that by having these discussions, processing in as real time as publishing allows and sharing this here - even the parts that are still in development - we establish and then consider the unique details and myriad connections between these periods to provide a historical and critical context for 
understanding the past and ongoing work of AIDS cultural production. It is important to note that the periods have porous boundaries, and a trend or pattern from any one can influence or can even be seen in the next. Furthermore, debating or even doubting their efficacy is a useful place to begin conversation, as is true here.

Ted: So, starting with our own experiences, reactions, and moods - often inspired by what we see in select objects of cultural production - we reflect upon how each period has its own notable feelings, technologies, and methods that were and can continue to be useful for AIDS activism and community.

Alex: This text is an edited selection from "Trigger," one of two sections of our book, in which we do our best to carefully detail the qualities of AIDS Crisis Culture by focusing on the tactics that can be found, reclaimed, and used newly from this critical period through careful interactions with salvaged video. In the book, the Bebashi tape demands nearly 100 pages of such effort!

Ted: Through this careful, exacting, and shared process we learn that tape, time, and technology are critical components of a method we define and model for AIDS cultural work, one that we call "conversational stewardship" that we model here: the cross-generational salvage and (re) use of generation, video, people, and their politics.

Alex: Conversational stewardship is a process that allows us to take time to watch, talk, and listen to materials salvaged from the past. We try to attend, with care, to what we see, how this is of its time and can be of ours, what others felt and knew before us, and what we need now as AIDS activists, in our difference from and shared commitments to each other, our present community, and our interlocutors from the past. We are doing it here: enacting conversational stewardship of the Bebashi tape as two white, cis-gender, HIV-negative, Western educated "AIDS-Professionals" and activists, each from different generations, as a model for using tape as a connection between people, time, technologies, and tactics.

\section{Final decision}

Alex: So let's get back to the tape! In the second section, we are introduced to a new actress: also African-American, but older and with short straight hair. She is sitting in front of what was the room divider in the previous scene, now serving as a wall. The sign behind her reads, "Shelter Rules." Again, the action starts on the phone, but this 
time the actress speaks centered in the frame and within a single long take, an impressive feat of acting and direction.

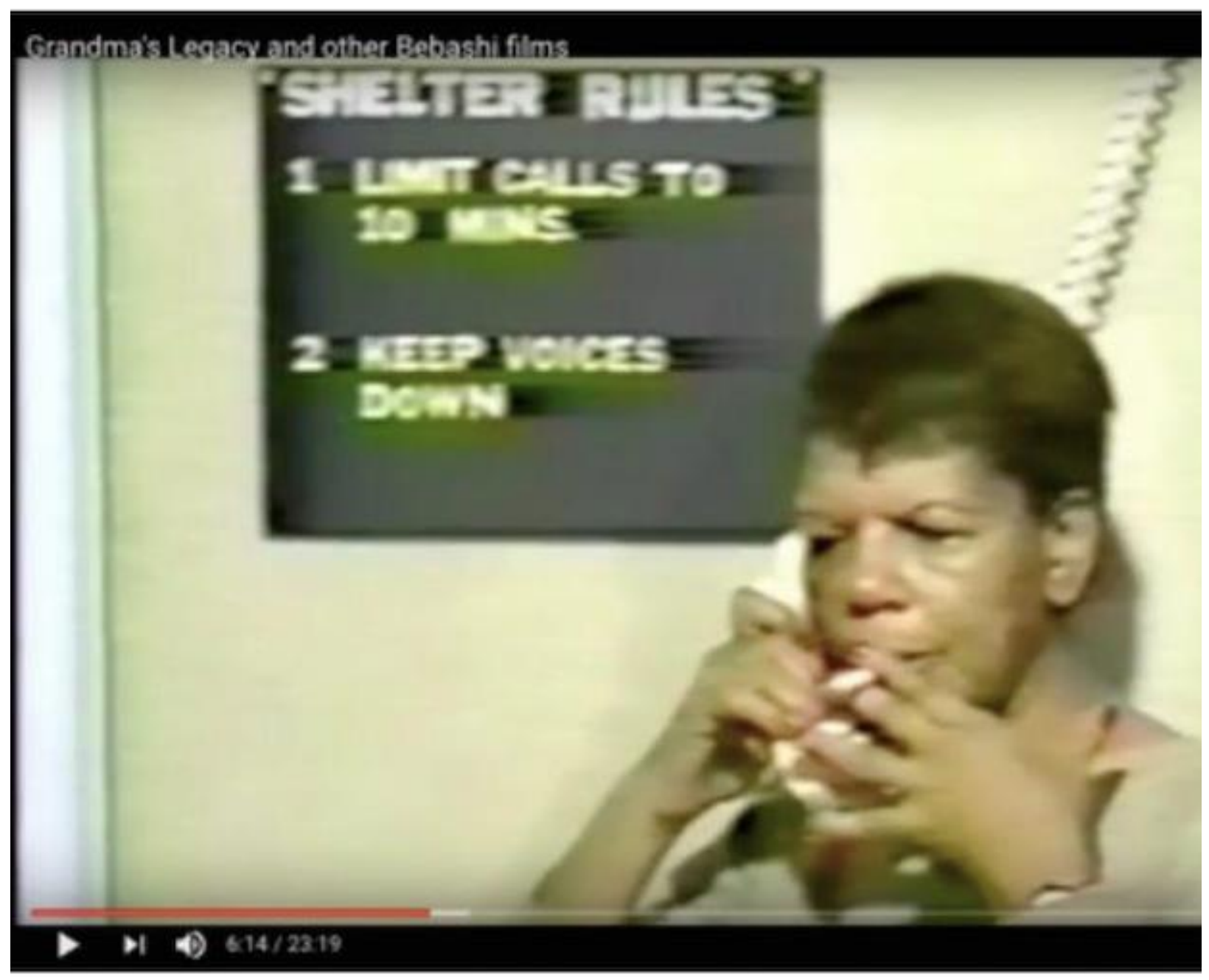

Figure 2: The second vignette, "Final decision," features a new actress on a different phone.

Ted: She is speaking with Spike, a man with whom she has a complicated and violent relationship. At first her tone is calm. She asks Spike to try to find her medical card. She needs it so she can get into rehab. As the conversation continues it is clear that she hopes to get the card with as little interaction with Spike as possible. Meanwhile, 
he is using the card as ransom. He wants to see her again. She remains carefully upbeat. As the conversation sways between her current needs and their shared past, she thanks him repeatedly for treating her well when they were both using drugs. But she also reflects upon when things between them weren't so pleasant, including the time he made her have sex with another man when they were both high and he watched. As the call continues, she begins to lose her patience and grows anxious about acquiring the card.

Alex: Unspoken but legible on her face is that her sobriety is new, valuable, and precarious. Seeing him, as her words and delivery make clear, would put her new and hard-fought health in danger. But there doesn't seem to be any other options if she is to move forward into rehab. 


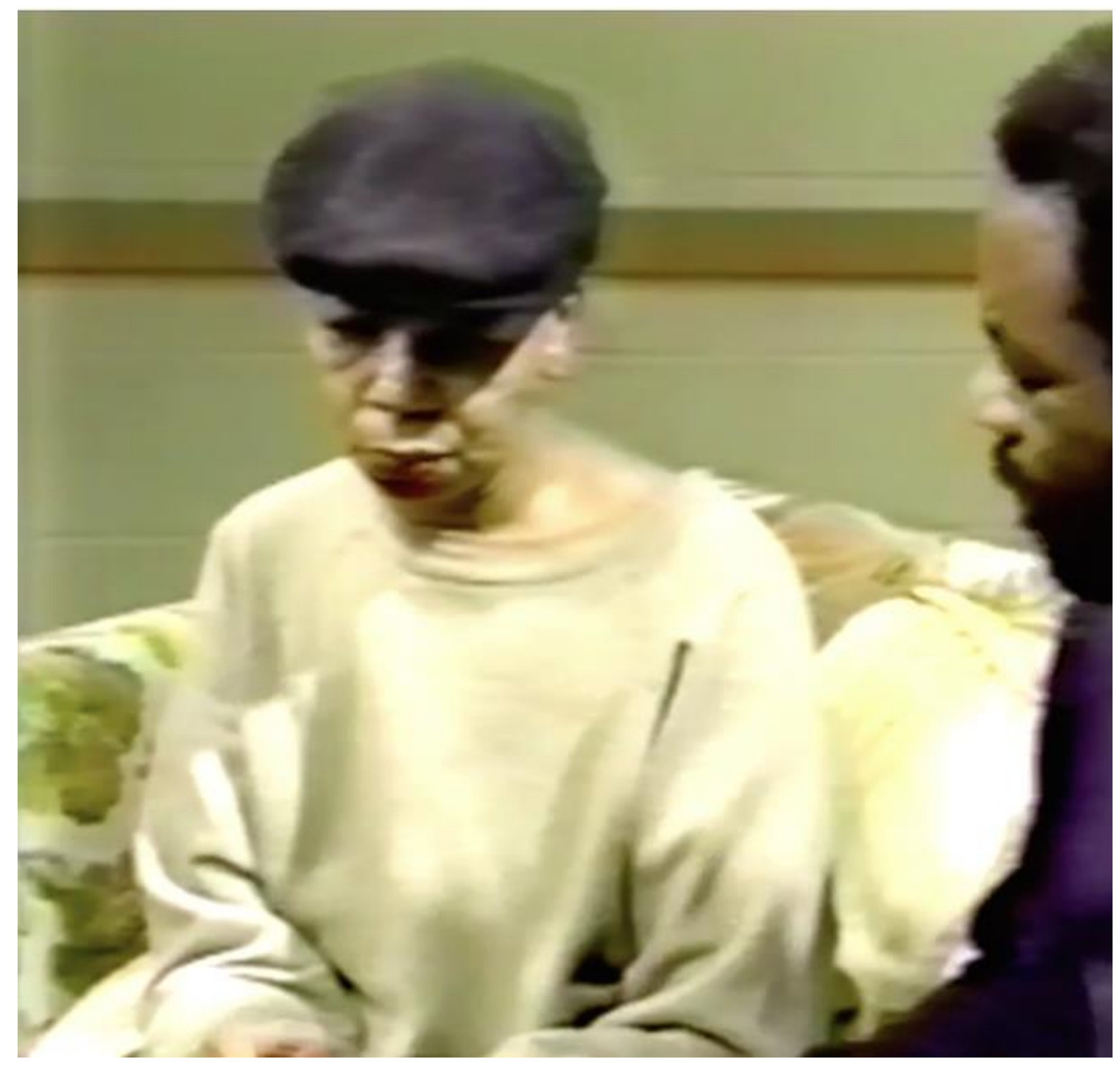

Figure 3: Within the second vignette, there is a second scene where we find the actress having to deal with her ex.

Ted: This episode has two scenes. When the second one begins we see that the nowfamiliar furniture has been rearranged yet again, this time to look like a different living room. The camera opens on lines of coke on a table. The actress enters, now out of the shelter and at Spike's apartment. She is wearing a cap and looks cool. He asks 
her to take a hit of the drugs on the table and she declines: "I told you I ain't get high no more." As was true for the man in the previous scene, this one is also aggravated, jealous, and demanding. He grabs her and begins to kiss her aggressively. She repeatedly asks him to stop. He continues, moans, and grabs her crotch. The camera pushes back to the drugs on the table and the scene fades to black over yet another unpleasant embrace and unfinished scenario.

Alex: Within the stillness and black on the screen, before any new visuals begin, and far outside the world of the vignettes, something disorienting happens. From inside the fade-out we hear the disturbing and lingering resonances of Spike's arousal: "Ah ... yeah ..." The vignette is closing on sounds of his pleasure at her quieted expense.

\section{Humane salvaging}

Ted: We want to reiterate that the information we have about the Bebashi vignettes comes from watching the tape itself - paying attention to the sights, sounds, and choices made by the people originally involved. Oh, and also the short paragraph you wrote about the tape 20 or more years ago, in your book AIDS TV, which I went back to read in preparation for this conversation.

Alex: And I didn't read the paragraph before we talked — although I easily could have - for reasons that are definitive of the many burdens and responsibilities brought about by knowing and passing on within cross-generational sharing. A question I bring to this work with you is, must I return to my past every time it is evoked? Is this my (only) job? People today, in the Revisitation, are particularly interested in looking at a history that I lived through, wrote about, and discussed for decades. I wonder, what are the costs to me or you if the things I have already done and also recorded are either revisited or lost? If no one cares? If people care but misconstrue, or bring their new words and judgments to works from before that can't quite hold our current critiques or needs? Why and also how do we carefully and caringly make, save, share, and revisit? To be clear here, this we is all of us in our small, interlinked but also diverse activist communities who are living, working on, and staying the course within ongoing social justice movements, in our case, HIV/AIDS. As it was true that the Bebashi tape went all but lost, I sometimes feel that about my careful work on AIDS TV. Sure some people read it, for which I am truly gratified, but even so, we all forget or gloss. Even me! I didn't really remember what I had written there, 20 or more years ago. 
"Humane salvaging" allows us our different, ambivalent, partial, and even contradictory relations to the past - as initiated by objects, but also as felt between and within us. We think that objects might be able to hold these competing needs and feelings easier than do people, but they function more as a transitional objects that give us permission to say, to ourselves and each other, what are our interests, concerns, apologies, and urgencies from the past and also in the present. Perhaps I am saying that everything that we do as cultural workers - making, receiving, sharing, interpreting, saving our activist inheritances - especially when we only have meager resources to support us, has two values, each precious: one is the power of all these processes as they are being done and lived; the other, related, is that these objects might engender new processes, and perhaps new objects that can do the same.

Ted: Which I think for you means that to begin to appreciate a work from the past, it must both be witnessed in the historical context it was created, and also respected as a live object in the present, with meaning, contradictions, questions, and answers of its time (like this one, the time of this conversation).

Alex: And, these responses to and needs from cultural production differ in ways that are significant, notable, and useful in their own right: across one's personal history and also between people in time. The humane part of this salvage of past objects starts with expressing human feeling about past things as experienced in community. For example, for me to participate in a meaningful way, allowing me to spend considerable energy with you on this one object while maintaining a keen eye and ongoing excitement, demands a trust in our process. We will return to what I wrote about this tape when I was 25 (30 years ago!), and that feels painful in a lot of ways: I can't remember most if it even though I lived and then also wrote it; and, if it is so easily losable I must ask, what is the use of this writing here, or any writing for that matter? Is it only or mostly for its doing, for its time? And harder yet, maybe it is not remembered because it wasn't good enough. But that is not to say that I don't want to engage, or consider, or be in conversation. After all, after we watched the DVD-dub of the Bebashi tape, I did look for the VHS tape. I successfully located it in a box on a shelf in a holding room in the library at Brooklyn College, where I had donated it, and many like it, to be archived professionally.

Ted: I think what you are saying about your relationship to the past is important for me to witness and valuable for me to consider. I am grateful that you are engaging in this project not just as a living record locator from the past, but as a person with a history as well as a contemporary practice of curiosity and knowledge production around AIDS. 
Alex: I don't need you to be grateful, Ted. That is not what I am asking for. What I am saying remains a bit overwhelming for me but also I think at the heart of what we are doing here.

Ted: What do you need?

Alex: First of all, this is not only about me. You also have a past and present. What do you need?

Ted: Like you, I need many different things, and right now, the most pressing thing is that I need to understand how best for us to work together. I also need to know that we have a process in place that allows us to be messy and remember that "time is not a line" [6], so that when I feel confronted or out of sorts, the conversation and our process can hold it, me, us.

Alex: And hold AIDS in its many times: ongoing, in the past, and the future! With that in mind, let me say this: not only did I live and work through all those times of AIDS, but like you, I had ideas and wrote them down and they were published, and I also made videos, gave presentations, had conversations. And I did this work within a vibrant activist community of other smart and energetic people, and we were learning from each other. We figured a lot out, and things were better in this time (AIDS Crisis Culture and now the Revisitation) because of it, even as AIDS continues and our friends died. And I feel good about that work as a person within a community, even as I and we also suffer our immense losses. And now, a few decades later, I am still a teacher, a writer, and an activist. I am still working on AIDS and related cultural and political issues. And I am frequently in spaces where I see people trying to figure out for themselves, for the first time, things that we learned and said to each other only decades earlier. People are engaging in their own AIDS cultural production which is building on our earlier work, and yet most often with little knowledge of it. And that is both human and also confusing and disorienting at least in relation to my lived experience.

Ted: Part of being in a movement for a long time is getting to witness shifts in understanding and how the production of culture can facilitate changes in knowledge $\cdots$

Alex: Yes, and related practices and experiences in the world as well as their facilitating technologies! Things change when empowered groups of people (even those on the margin, even small groups of people, even those too little and undersupported) make work with new, if connected, ideas and demands, as abetted by machines and systems. 
Ted: And for you, there is a sense of unsuredness about how to deal with being that witness, especially while engaged in conversation with someone like me, who you may consider a peer, but one who has different and less experience than you.

Alex: I'm both witness and actor at the same time. That's disconcerting. These are different and sometimes competing roles. And, it's not that you have "less experience" than me. Just less time on this earth and in our movement. You're a 41year old man. You have reams of experience. I am often learning from you, as you know. That's why we have been in conversation and friendship for so long. And I started working on this when I was 23!

Ted: I also started AIDS work when I was in my early 20s, but in a different mode and a different period. Thus, an important part of our conversational stewardship is to honor that we feel and know differently even when we were participating in the same AIDS epoch. One object will mean many things, as does one epoch, to each of us, and to understand the variety of our responses and experiences we need to trust and learn from each other. I think I now have some better sense of what it is like for you to wonder how to balance dragging forward the past into the present.

Alex: I am not a relic even if I must be an "elder." I am still doing the work in the present, and I also happen to have prior knowledge as well. We have engaged in this work together for many years now, and this has been within a larger milieu that is both diverse and devoted to reckoning with AIDS with passion, dignity, and power. To do this work we have to see each other as people with a past and a present, in a community that has had many iterations, and sometimes we have to repeat ourselves, even if the echo is two decades and painful in its coming (again).

Ted: And this has to start somewhere or with something. So, finding and sharing the Bebashi tape is helpful.

Alex: This tape was one of about a hundred that I collected and watched in the late 1980s as part of my doctoral (and activist) research on AIDS activist video. I was in my late twenties and living in New York. These research materials came to me in a variety of ways: through friends and colleagues who were also AIDS video activists, by reading through lists of AIDS video collections built and maintained by non-profits and public health organizations around the US for their clients who needed information and insight, from gay and lesbian film festivals where some of this work was screened, and even from the art world where there was a keen interest in activist AIDS arts in certain quarters. My files for my dissertation are filled with lengthy and heavy print-outs of lists of video holdings that catalogue collections of AIDS videotapes that were being built and shared all over the world. Today, such lists (and media) would be found online, and would be easier to get to. But the care and time 
that is registered in the handmade lists and the material holdings that people acquired and cared for gets lost in digital settings, as do the uses and meanings of AIDS and its technologies which are engendered in these spaces. When everything is easily available a certain kind of useful preciousness and focus, which is particularly valuable for activism and education, can go lost.

Ted: As is true today, during AIDS Crisis Culture there were a great many cultural workers who were writing, thinking about, showing, or making AIDS video, inside and outside of academia, art worlds, non-profits, health organizations, activist communities, and elsewhere.

Alex: Sure, but what I want to say here is that a significant aspect of our activism was simply getting this material to each other: on tape, via lists, in rooms, writings, and padded mailers (but without Amazon doing the shipping!) This large, multi-faceted, materially based movement around video was the subject of my dissertation.

Ted: Not to get us off track from the flow of your story, but issues with dissemination still continue. Transportation, via hateful Amazon or the Internet makes life easier, but does not guarantee viewership or engagement.

Alex: Point taken. Dissemination and engagement differ in time and because of technology. I know this because in 1991 I got my first full time academic job and left New York. Like so many who lived, I moved on and became pretty quiet about AIDS for a decade or more (this is during the period and also is evidence of what we call the Second Silence). It is not that I thought that AIDS was over, it was that the urgency had somehow been evacuated from the movement and its dissemination and engagement slowed down. A lot. But, even so, I lugged these VHS tapes and many more with me when I moved to LA in 1995 to teach in Claremont. Then, quite recently, I brought them back across the country when I moved to NYC in the summer of 2016 for my new job at CUNY.

Ted: Which is when I first had a chance to watch the video, with you, in your then only recently unpacked living room.

Alex: This was the beginning of our face-to-face working conversations (we had worked together before, but always using phones or computers). Now that I was in Brooklyn, and we had become inadvertent neighbors, we began to meet regularly in the domestic space of my living room, and this usually included breakfast, gossip, and important catch-ups on the sprawling contemporary AIDS activist cultural landscape we are both navigating (and co-creating with others) in NYC. We were - and are part of a dynamic, expanding conversation about AIDS cultural production. 
Ted: This is our process - and our belief — that AIDS archival work is best done in conversation, between people, times, technologies, and modes of understanding.

Alex: This is an approach to tape and time much like the one I asked you to use to consider me: I am of the past and the present, as long as I am alive. So is our movement's vast, diverse, and changing cultural production. As someone who has made many concerted efforts to save and also carry these three scenes forward by salvaging, transferring, sharing, and rewriting about this one particular VHS dub, I also feel some responsibility to convey history about how the tape was known and viewed in the past. So, let's keep at it.

\section{Grandma's legacy}

Ted: As the last of the three scenes begins, we see the same actress from the previous vignette, but she has transformed. It is not clear if she is playing the same character again. Her hair is no longer straight, and it is a different color.

Alex: The establishing shot is of two women; one is holding a video camera. Violent men no longer dominate or even enter the scene. Instead, seated across a table from the woman we recognize from the previous story is another Black actress, much younger. She is holding a video camera. We learn her name is Keisha, the daughter in this scenario. When she first speaks, the point of view switches from the establishing shot of the two women together. The two cameras (hers and the one taping her shooting video) are now serving as an intergenerational bridge. We see a blurred close up on the older woman's face as it comes into focus, as if from the perspective of Keisha's camcorder: she's attending with a keen tenderness - much as we are now - to the stories, words, needs and problems of this one Black women in crisis, in Philadelphia, in the late 1980s. The perspective switches once again and we see Keisha: "Come on Mama. Say something please, we said we'd do this for the kids." 


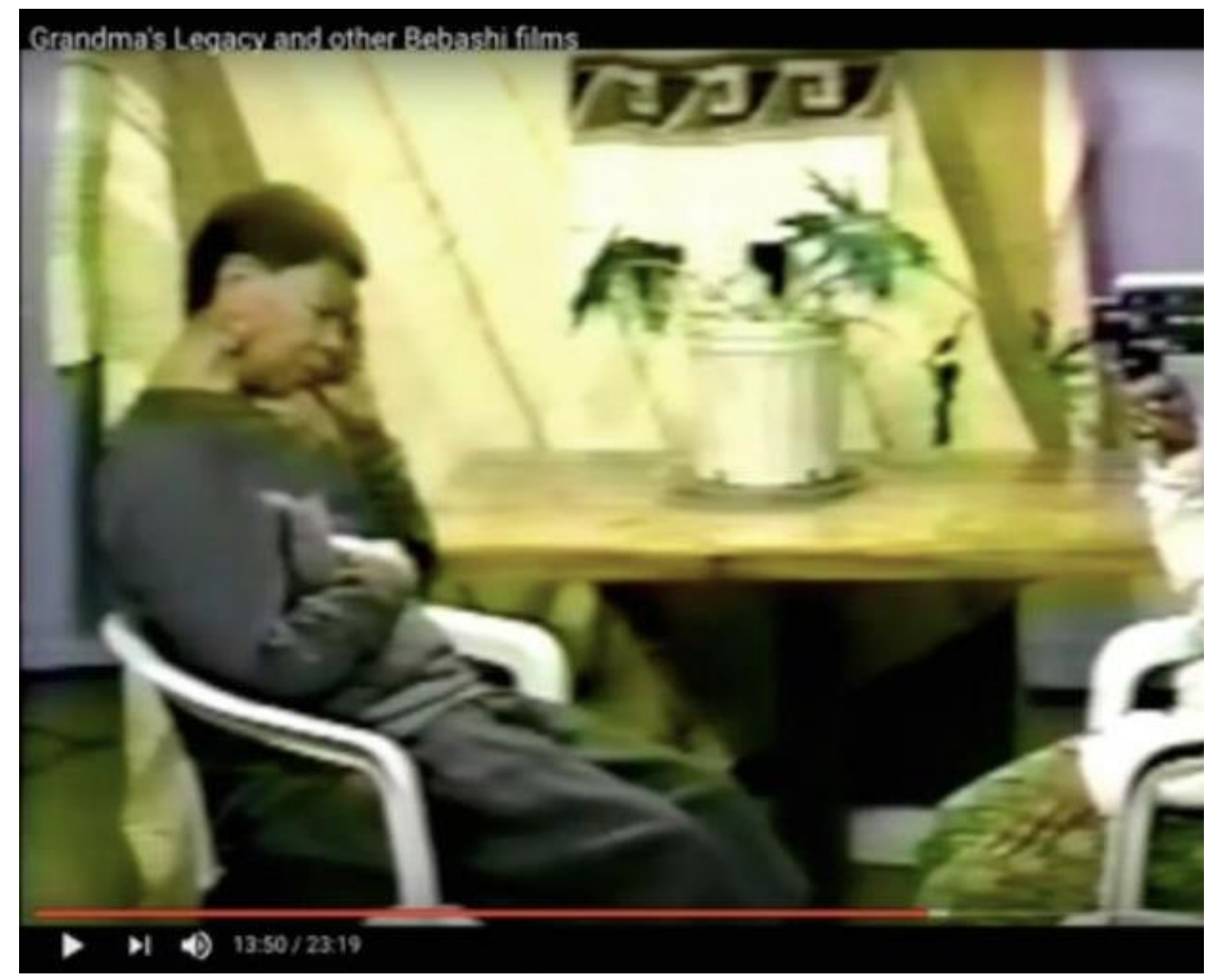

Figure 4: Keisha and Miriam Bennett recording for posterity one "Grandma's legacy."

Ted: The mother and daughter have come together to shoot a video interview using the daughter's new camera - an expensive but necessary indulgence that we learn cost them a lot: $\$ 900$. The camcorder was bought to capture this story for posterity "I am Miriam Bennett" — and it is used, as planned, to record her as she explains that she has AIDS and is not sure she will live long enough to meet her grandchild and pass on her legacy in person.

Alex: To state the obvious, the three vignettes use video to deliver their message for an anticipated future. So with this last scene, with the specter of death now on the 
horizon, we experience a doubled act of taping and generation-saving as catalysts for hard conversation between many groups of people: the mother and daughter in the present of the story; the fictional progeny in the video's future; the actual intended viewers of the educational tape by Bebashi in the 1980s, women from urban Black communities like the one depicted in the scenarios; and now us, a different, perhaps unimagined if maybe also anticipated duo of viewers in the future; and then too, you, the readers of our intergenerational conversation.

Ted: It is also in this final scene where the three vignettes really come together. If video is used to talk about the experience of Black women in Philadelphia, it is also used to show how HIV is not unrelated to the issues of domestic violence and drug use that have preceded.

Alex: We learn that Ms. Bennett contracted HIV from an abusive lover, Bill, who she had caught trying to rape Keisha when she was a little girl.

Ted: This is an echo of the first scenario that also pictures a mother doing what she can to protect her child from domestic violence. In this later scene, we learn from her exposition that when she became aware of Bill he was already attacking Keisha, and so she needed to spring into action; she knifed him several times to stop him.

Alex: Miriam Bennett continues her story staccato between sobs. Her last line is a lament:

Who would have thought that I would be dying of AIDS. Ain't that the shit. I get my ass kicked for six years, barely save my child from a rapist, move out, finally get my life together, and the minute I get a case to haul off, and I be dying.

Ted: The scene ends with Ms. Bennett burying her face in her hands and with both women crying as Keisha calls out, "Mama ... Mama." While the tape fades to another black, my feelings are left very live. On your VHS dub of the vignettes, the sound and the image cut off together. There is a quick dip to black and a flurry of grey static before the screen goes to video blue. The word "PLAY" appears imprinted in the corner; a fitting conclusion: an invitation to stop, shake your head, take a deep breath, look around, and begin to make sense of all that was just seen.

Alex: What we have witnessed is so hard. We need time and space to process. This may also be another reason why this tape, like so many like it - those made by, for, and about women, people of color, children, families, and so many others for whom HIV merely intensifies violence, marginalization, and self-doubt - goes so easily lost. 


\section{What is a trigger tape?}

Alex: This tape is from a now lost sub-genre - trigger tapes - made to be used in educational settings and therapeutic contexts with trained facilitators.

Ted: Funny, isn't it? Trigger is a word that has - for better or worse - become overly associated with warning someone about content, allowing them to decide if they want to opt out of conversation or viewing. You are suggesting that it was once an invitation for initiating hard-to-have discussions.

Alex: Silencing was never our thing. Silence equals death, remember?

Ted: I remember! But trigger warnings are not silencing, are they? Aren't they about providing choice, and respecting that trauma is real, something we could argue is as paramount to AIDS activism as "Silence = Death."

Alex: Yes. And if we are to respect current parlance and norms, this trigger tape would itself need trigger warnings given how the vignettes sit entirely within sites of trauma: domestic settings defined by physical abuse, coercive drug use, and premature death. In the video's original time, however, a favored way to respond to trauma was to open into it within a supportive environment. To name and see it, together. But these differences signal that we demand changing healing practices around witnessing, visibility, and media as technology alters in relation to the ease with which we can record, share, and save images.

Ted: Agreed. Every generation grapples with their own technological advances. Today we have to deal with what to do as more information becomes unfettered, less censored, more available. This influx of representational possibility initiates the current cultural calls for slowing down and pausing. Maybe trigger warnings are as much about the real and traumatizing content that can so easily float past someone's field of vision, as they are about creating some sort of dam on content, a levee to ease the breaking tides.

Alex: Unlike the Internet culture and media spaces of today - a world of representational abundance in need of boundaries - the world we were hoping to make or at least see newly during AIDS Crisis Production, where our newfangled and empowering medium was VHS video, was organized by an almost complete and just- 
breaking silence: who couldn't or wouldn't speak because testifying would have meant certain danger or there was a sense that no one was listening.

Ted: Which is where technologies of testimony come in. When people come together to bear witness to each other, language, understandings, and I would say narratives, emerge.

Alex: Yes, and with the Bebashi tape, we watch three connected but separate testimonies meant to be witnessed and also processed as three stand-alone stories. This was meant to happen in a context different from, and well outside of, the dangerous homes being depicted. All of the homes we get to see are depicted as unsafe - due to violence, drugs, patriarchal control, and systemic racism. A productive screening of the tape would attempt to create some safety within which a more considered response to the dangers depicted could take place, one not possible during a real crisis in similar real-world scenarios.

Ted: It was not to be watched as one steady unroll, as if it is one tape rather than three.

Alex: Exactly, and this kind of slowing-down (as per today's trigger warning) would happen in a church basement, community hall, or doctor's office waiting room for a small handful of people, probably women, whose lives should not be much dissimilar from those depicted on the screen. The end of each scenario is left unplayed because the intention is for the viewers, as individuals and as a group, to help each other to play out the characters', and really their own, next steps. At a screening of a trigger tape, after each vignette a facilitator starts a conversation about what has just been seen. The emphasis is on inviting connections between the scene and people's lives. The tapes were made to move audiences of highly specific viewers into personal and also collective understandings about the struggles and realities of their own experiences: for example, what is at risk for them personally, in their own homes and families, when and if they decide to negotiate safer sex with a male lover, partner, or husband. So much early activism around women and AIDS had to center on women's vulnerability, lack of agency and self-confidence, and the socio-cultural-religious frameworks that give men permission to demand sex on their terms, that is, without a condom.

Ted: The process of trigger tapes is an interesting response to the acknowledged structural creation of fragility.

Alex: No one making activist tapes at that time thought that women were inherently weak. Rather, there was a hard-won feminist understanding, begun generations earlier, that we live within interlocking or intersectional systems that create inequality, and part of the work is naming those inequalities and their connections to each other and 
the lived possibilities of women. Only then, to use a contemporary phrase, could we hack the system to help even-out the field. Trigger tapes bore witness to inequality while providing a structure for agency.

Ted: So, can we understand a trigger tape as something like a Web site, a place for content and interaction?

Alex: Simply: no. This comparison does not capture the ideological foundation of collaboration and on-the-ground education and movement-making that was at the heart of trigger tapes. A technological, political, representational reality about the first period of AIDS Crisis Culture is that it was social, interactive, and shared. In this sense, it was the communal making and watching of trigger tapes (and most other AIDS activist videos) - the studying, learning, sharing, and politicizing necessary to get to, make, share, and engage with still rather hard to-see video - that contributed most to our social change goals.

A trigger tape is not a Web site because the process of making and watching is collective and collaborative by definition. Today, a Web site at best results in private aha moments that are probably interchangeable or hard to hold on to, given the guarantee that another will so quickly follow. Political impact, educational impact, artistic impact have been privatized in production and reception, to be linked technologically, yes, but in a way that creates an immediate but harder-to-sustain power and buzz.

Ted: Right, so the idea of people together in time and space is really important. A trigger tape was about being together in process, witness, and growth.

Alex: Which is part of the longer history of moving images, and the current moment of our interaction (first as viewers, now as writers)! Media once brought and can still bring bodies together.

Ted: When you put it that way, it reminds me of Dirty Looks (DL), the film screening series that was started eight years ago by Bradford Noreen and friends. Early DL collaborator and guiding force, Karl McCool once gave some background about their goals: "When Dirty Looks started we were inspired by this idea of film societies and cinema clubs in the 60s in the New York Underground, this idea that artists and cinephiles and the general public would come together in a social space and experience experimental film, not as a museum piece but as part of community." [] Which then makes me think of Stefano Harney and Fred Moten's definition of "study," which Moten shares in an interview with Stevphen Shukaitis: "I think we were committed to the idea that study is what you do with other people. It's talking and walking around with other people, working, dancing, suffering, some irreducible 
convergence of all three, held under the name of speculative practice." [ 8 ] That seems closer to what you are getting at.

Alex: That's really useful, Ted. And that is a present-day example that helps clarify what I mean! In the 1980s and 1990s, more so than it seems now, AIDS (and much else) was lived as a collective experience. So yes, in the working, dancing, and suffering of our lives together we were "studying." We had no choice. Before the meds came out in 1996 (the period we call the Second Silence, a decade after the HIV antibody test arrived and 15 years after HIV was first "discovered"), we not only lived with HIV together, but we also responded together in self-made, sometimes interlocking corners of a community-produced world of AIDS and also its representations. Because there was less total representation (about anything), because video was harder to make and show than it is now (although much easier than making film, the reason why so many of us gravitated to video at that time when consumer camcorders and editing first became available), because distribution wasn't as easy to facilitate and so tapes were not so readily accessible, people mostly watched things together on screens or monitors, and our videos were often held in carefully curated collections to be made available to others who needed them (like mine!). We made and watched video communally and in conversation with our allies and friends, our larger if still specific intended audiences, and those viewers who got to them in their own, unanticipated ways.

With the three vignettes we just watched, the quality of the tape pales in comparison to the caliber of interaction that it reveals and can also stimulate. Our goal was to make something that we were proud of, that we could show to each other, and that would be of use. And, the making of the video was where a good deal of where the world-making was taking place: naming things, choosing what to highlight and share, hashing-out analyses and stories together, being willing to self-represent in a time where this was rarely done for any person on their own terms or by themselves, let alone for disenfranchised people like women of color, trans or poor people, drug users, victims of domestic abuse, or people ill and dying: the communities always at the heart of AIDS stories of both tragedy and potential empowerment.

Ted: I want to back up a tiny bit, and push back on the idea of then versus now when it comes to collective experiences. I don't think it is true. I think what we are talking about is that regardless of the epoch, people need human engagement so that they can build, care, and create themselves, and their worlds. Maybe you have a sense that when it came to the early years of AIDS there was a more collective understanding of the virus - which I can understand - but one could argue now, because of the Internet, there are new kinds of collective experiences of living with HIV and other terminal illnesses. Activists who can't leave their apartments, let alone their beds, can 
coordinate and participate in actions in real time, in ways that technological advances have made easier.

In Jennifer Brea's 2017 documentary Unrest [9], we see people living with Myalgic Encephalomyelitis (often referred to as Chronic Fatigue Syndrome [CFS] or ME/CFS) all across the U.S. who are using Skype to organize national protests. Some of them attend the protest in person and others participate from their beds. In fact, Brea herself does many of the interviews for her video from her bedroom. Community around illness is formed through computers and also video. I also want to mention here the Canaries [10], a group of women and femmes living with chronic illness who support each other through an online forum, and at times shared art practices, like the 2016 residence they had in New York's Recess space.

Alex: I appreciate you bringing them in. I want to be clear here, I am not performing some tired activist argument like, "back in the day is when we really knew how to organize ..." Rather, I am more interested in thinking about changes in policy, activism, or technology come with both possibilities and limits. This is something our friend Jih-Fei invited us to consider after reading a draft of our essay. He is interested in how the activists in Unrest and the Canaries demonstrate how technology can be used toward intersectional coalition-building and collectivity. Building from this, I want us to think about, when using or watching media, these related questions: "who cannot be represented" and "who cannot be present"?

Ted: I am glad you are bringing up Jih-Fei's insightful comments. Not only because they add to the conversation, but also because it is a reminder that more discussion is better. Connected to our earlier conversation about your role in these discussions, that I often feel a sense of uncertainty about when it is useful for me to question, inquire, or push back on lessons from the past offered by people like you who lived it. Which is not to say I am treating you or anyone with kid gloves or choosing deferment over engagement. Rather, there are times when someone will say something that is true to them about a time gone by, and will also attempt to apply this knowledge to the present. Then, I have to calculate when it is useful for me to talk about the present, or instead, when is it okay for someone like you to learn this more slowly, over time, and maybe not from me. For example, in this case, while there is truth and power in what you said, at the same time I don't want people reading this conversation to think that we don't know that there are legions of communities who have a collective understanding of HIV or illness today.

Alex: Indeed, as someone whose current work is about striving for queer feminist Internet culture, I think about and attend to the movements of communities that I care about into online spaces [11]. In this work, my stated concerns about the changing norms of mediated interaction are primarily about how and if they afford for being 
together in physical space (and/or shared time). That is what a trigger tape does so very well (when watched as it was meant to be, together with a selected group of viewers in a room with a facilitator). It pulls bodies in a room together, at least for that moment, and the video can serve as a tool towards an unpacking and an unflattening of each person's experience of the AIDS crisis: to make it more relevant, less overwhelming, and not avoidable, especially in communities that have been in denial, quiet, or outside representation.

And maybe this is why it is vital for us to talk about trigger tapes. They take up a unique, largely forgotten, yet still needed space within the world. You tried, but I am not sure we can or need to find a contemporary technological stand-in for trigger tapes or any kind of media made back in the day. This is what I was trying to say earlier about what I view as my role as someone from the past. Sure, I can tell you how it was, but I would rather do what we have done here: explain and listen and try to understand, the best that we can today, past works' content, the processes through which they were made, their intended meanings and uses within the context of their creation, and how that itself is in dialogue with what we see and need now. I strive to engage meaningfully with earlier video, with you and also our readers, through attempts to understand the Bebashi tape on its own merits and within its own contexts, which include the merits and contexts of the present.

Ted: That seems important.

Alex: As much as I have a multifaceted relationship to how I want our work from the past to be understood and considered in the present, I don't want the politics and influences of the past to get lost or be conflated with those of today, or to be understood as more valid. That's why I didn't go back to read my own book. I wrote that then! If you're interested in what I thought or knew then, go read my book. I did a lot of work when I was younger so that others might learn from it. It turns out, that's mostly lost. People need to learn things again, in their own time, in their own contexts (including me, again, now, with you), because it is through communal learning - in our lived present - that contemporary purpose and connection is defined, produced, and maintained for the living and the fighting. Sure, in some ways, that's a burden, and a heavy lesson: what you made before is made for its time, and to be forgotten, and only maybe to be refound or redone. But that is also at the heart of our theories and practices of conversational stewardship: capturing or holding is never enough nor really the point. It is the connecting, sharing, and changing of people through objects that matters (to people).

Ted: Yeah, I hear that. Things have to be read, seen, and considered in the present, and yet with an understanding that they were not created for you now in a vacuum. I think we are doing that, or at least I am trying. 
Alex: So, when you work hard to help find a contemporary way to understand trigger tapes, such as through comparisons to Internet culture, I want to join you in that. I live and use media now, too. My media use has changed with the times and their technologies. My students ask me, and I give trigger warnings.

Ted: Right, and as your media use has changed, you have changed. But I think a key to doing this work is to allow for a reset button to be pressed on the knowledge we have accumulated and allow a return to source, if only as a refresher.

Alex: Hit "Play," as our dub suggested ...

Ted: Right! When I teach about AIDS, be it in a university class, or a workshop setting, I like to begin with "how do we know what we know" about HIV. This helps to name our own specific, personal lens or bias, allowing us to share our ignorance as well as our expertise. It is also a good way to think about cultural production: What informed this video or that essay? Where is it coming from? And then, what am I or we bringing to it? Until this conversation, I never realized that this is what we might call a triggering exercise for ideas, connections, feelings, and ways forward.

Alex: Isn't that our goal? Isn't that why we make work, leave the house, go on a bagel walk, come together, write a conversation? That is why I appreciate all the various burdens, experiences, ignorances, and knowledge we bring to, change, and grow through this conversation. Along with what I need from the tape, I need to hear who we are and what we know and still need. This is hard, and deep, and it demonstrates that there is a difference between human connection and technological connectivity. 


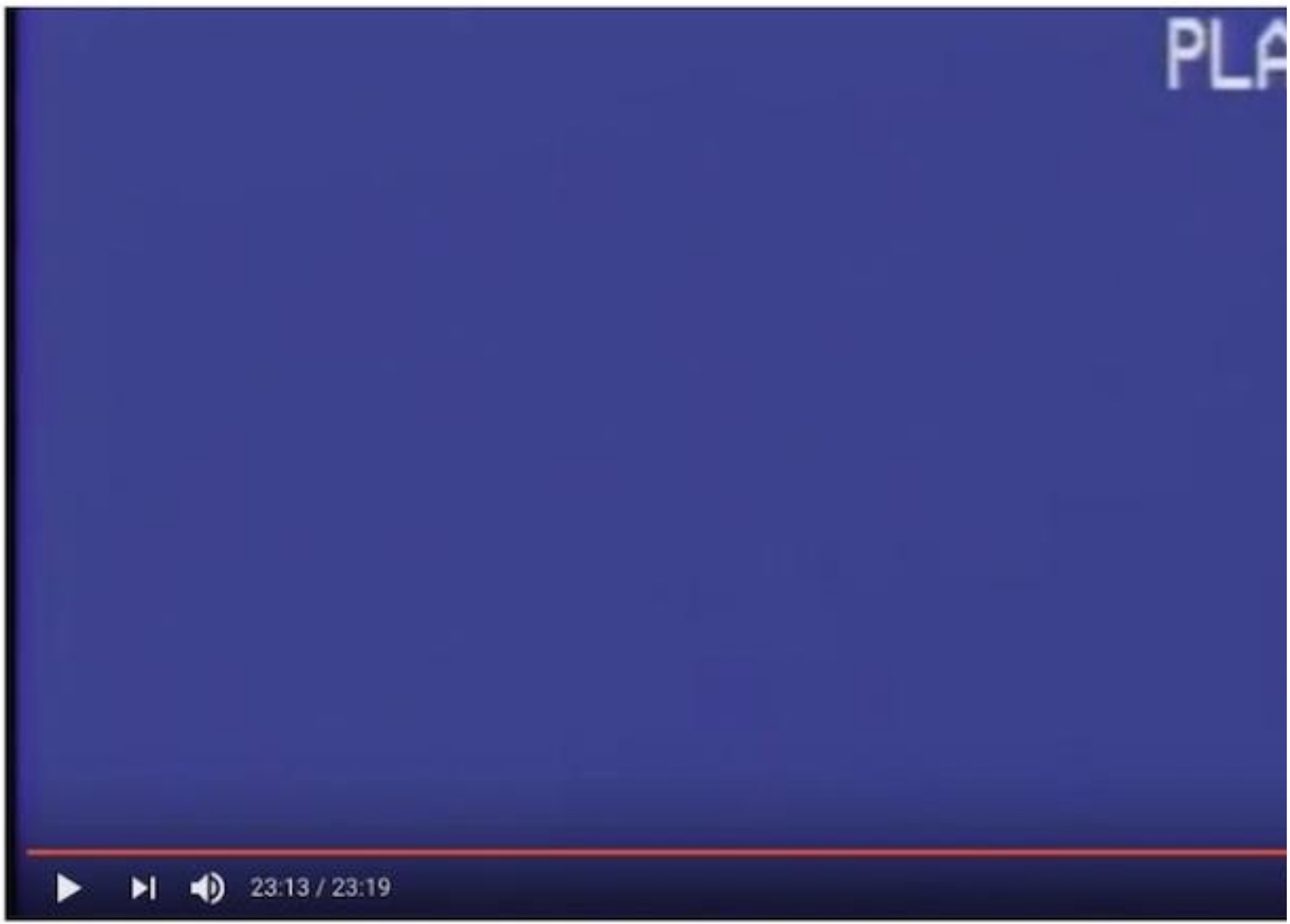

Grandma's Legacy and other Bebashi films

56 views

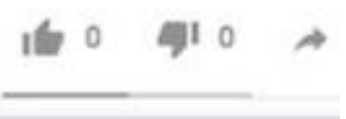

Figure 5: Grandma's legacy and other Bebashi films.

\section{Trigger}


We have uploaded the Bebashi video online (https://www.youtube.com/watch?v=jaxGoZqhYtE). When screened together the three vignettes are 30 minutes long. You are invited to watch the tape, ideally with someone else. As we have done, share what you have seen, what you know, what you still need. What ideas, concepts, and feelings does the tape bring up?

We watched the Bebashi tape together, in Alex's home, and then many more times alone on our computers. Your experience - as Shaka McGlotten, another peer reviewer for this journal pointed out to us after reading our text - will be different. So, make sure to consider the context of viewing the tapes on YouTube. Where are you watching? Are you alone? In public? How does the specificity of the platform impact your viewing - what ads are on the site next to the video, what is the next tape YouTube connects you to? Then how, as McGlotten invites us all to consider, might your viewing impact the platform and other's viewing of the tape? What comments will you leave? Will you share it? With what device, on what platform, with which hashtags or caption? What ways could we and should we tag or share the video? Should we share it on social media at all? Is it possible to communicate all the context we share in this conversation through an online interaction?

In terms of context, we also invite you engage in any of the suggested text and video resources following. While our conversation is rich and far reaching, it is built on a foundation of work that has come before. $\mathrm{Em}$

\section{About the authors}

Dr. Alexandra Juhasz is Distinguished Professor of Film at Brooklyn College, CUNY. She teaches, makes, and studies committed media practices that contribute to political change and individual and community growth. She has a Ph.D. in cinema studies from NYU and is the author of AIDS TV: Identity, community, and alternative video (Durham, N.C.: Duke University Press, 1995); Learning from

YouTube (Cambridge, Mass.: MIT Press, 2011), and My phone lies to me: Fake news poetry workshops as radical digital media literacy given the fact of fake news (The Operating System, 2020); editor of Women of vision: Histories in feminist film and video (Minneapolis: University of Minnesota Press, 2001); co-editor (with Jesse Lerner) of $F$ is for phony: Fake documentary and truth's undoing (Minnesota, 2005); co-editor (with Alisa Lebow) A companion to contemporary documentary film (Wiley-Blackwell, 2015); co-editor (with Yvonne Welbon) of Sisters in the life: A history of out African American lesbian media-making (Durham, N.C.: Duke University Press, 2018); and, co-editor (with Jih-Fei Cheng and Nishant Shahani) of AIDS and the Distribution of Crises (Durham, N.C.: Duke University Press, 2020). 
She is the producer of educational videotapes on feminist issues from AIDS to teen pregnancy and the feature narrative films The watermelon woman (Cheryl Dunye \& Dancing Girl Productions, Inc., 1997) and The Owls (Dunye, 2010). Her current work is on and about the feminist Internet including YouTube, pedagogy, affect and fake news.

Web: alexandrajuhasz.com.

Theodore (ted) Kerr is a Canadian-born, Brooklyn-based writer and organizer. His work focuses on HIV/AIDS. He is a founding member of What Would an HIV Doula Do? He edited the Fall 2019 issue of On Curating entitled, "What you don't know about AIDS could fill a museum." He was the Programs Manager at Visual AIDS, and graduated in 2016 from Union Theological Seminary. He has organized AIDS related events with the Brooklyn Museum, New York Public Library and many other organizations; his writing has appeared in the Village Voice, Women's Studies Quarterly, Lambda Literary, HyperAllergic, and his conversations with Alexandra Juhasz, Bryn Kelly and Claire Barliant have been published through IndieWire and Cineaste. He teaches at the the New School. He and Alex Juhasz are working on a book project tracing the cultural history of AIDS.

Web: www.tedkerr.club.

\section{Notes}

1. You can follow the teaching, saving, and sharing of Alex's scholarly and activist VHS collection in a series of connected projects: her co-taught graduate class with Jenn McCoy, VHS archives: Artistic process in contemporary community, at Brooklyn College (https://scalar.usc.edu/works/film7032/index), and her CUNY Graduate School Center for the Humanities' supported working group, also called VHS Archives (https://www.centerforthehumanities.org/public-engagement/workinggroups/vhs-archives).

2. Since the time of this conversation, and as part of our larger book project, Ted visited the offices of Bebashi-Transition to Hope, and learned more about the tape, the organization, and contemporary AIDS activism in Philadelphia. Stay tuned!

3. AIDS TV: Identity, community, and alternative video (Durham, N.C.: Duke University Press, 1995).

4. See Stacked on her office shelf: Stewardship and AIDS archives where we think about archive gatekeepers through the lens of Grandma's 
Legacy: https://www.centerforthehumanities.org/blog/stacked-on-her-office-shelfstewardship-and-aids-archives.

5. Previous writing includes: "Home Video Returns: Media Ecologies of the Past of HIV/AIDS," Cineaste (Web), 2014, https://www.cineaste.com/summer2014/homevideo-returns-media-ecologies-of-the-past-of-hiv-aids/; "AIDS Reruns: Becoming 'Normal'? A Conversation on 'The Normal Heart' and the Media Ecology of HIV/AIDS,” IndieWire (Web), 2014, https://www.indiewire.com/2014/08/aidsreruns-becoming-normal-a-conversation-on-the-normal-heart-and-the-media-ecologyof-hivaids-216116/; "On Care, Activism, and HIV," Hematopoiesis Press (Web), 2017, http://hematopoiesispress.com/on-care-activism-and-hiv; "Stacked on Her Office Shelf: Stewardship and AIDS Archives," The Center for the Humanities, The Graduate Center, CUNY (Web), 2017, http://www.centerforthehumanities.org/distributaries/stacked-on-her-officeshelf-stewardship-and-aids-archives; "Who Are The Stewards of the AIDS Archives: Sharing the political weight of the intimate," in The Unfinished Queer Agenda: After Marriage Equality, 2018 (book chapter); "Seeing What the Patrimony Didn't Save: Alternative Stewardship of the Activist Media Archive," in InsUrgent Media from the Front, 2020. (book chapter); "AIDS Normalization," X-TRA, 22: 4, Summer 2020, https://www.X-traonline.org/article/aids-normalization; "Silence doesn't

Rhyme, But it Repeats: AIDS, BLM, COVID-19, and the Sound of What is Missing, a conversation in 4 parts," Duke University Press Blog, Summer 2020, https://dukeupress.wordpress.com/2020/08/06/dispatches-on-aids-and-covid-19continuing-conversations-from-aids-and-the-distribution-of-crises-dispatch-three/.

6. Ted uses the phrase, "Time is not a line" for the 2014 issue of the We Who Feel Differently journal (a project of artist Carlos Motta). The issue focused primarily on AIDS related culture coming after the Second Silence.

7. From the Visual AIDS event, "(re)Presenting AIDS: Culture and Accountability": https://visualaids.org/blog/karl-mccool-from-dirty-looks-atrepresenting-aids-culture-and-accountabilit.

8. "Studying Through the Undercommons: Stefano Harney \& Fred Moten," Interview by Stevphen Shukaitis: https://classwaru.org/2012/11/12/studying-through-theundercommons-stefano-harney-fred-moten-interviewed-by-stevphen-shukaitis/.

9. Learn more about the video, including where to watch: https://www.unrest.film/.

10. Learn more about the Canaries: www.instagram.com/wearecanaries.

11. See, for example, http://www.feministonlinespaces.com. 


\section{Articles}

- Jih-Fei Cheng, 2019. "AIDS, Black feminisms, and the institutionalization of queer politics," GLQ, volume 25, number 1, pp. 169-177.

- John Greyson, 1990. "Strategic compromises: AIDS and alternative video practices," In: Mark O'Brien and Craig Little (editors). Reimaging America: The arts of social change. Philadelphia: New Society Publishers, pp. 60-74.

- Ray Navarro and Cahterine Saalfield, 1989. "Not just Black and White: AIDS media and people of color," Independent (July), pp. 18-23.

- Frances Negron-Muntaner, 1991. "The ethics of community media: A filmmaker confronts the contradictions of producing media about and for a community where she is both an insider and outsider," Independent, May pp. 20-24.

- Debra Levine, 2002. "Another kind of love: A Performance of Prosthetic Politics," Sexualities and politics in the Americas, volume 2, number 2, at https://hemisphericinstitute.org/en/emisferica-2-2/2-2-essays/aperformance-of-prosthetic-politics.html.

\section{Books}

- Yvonne Welbon and Alexandra Juhasz (editors), 2018. Sisters in the life: A history of out African American lesbian media-making. Durham, N.C.: Duke University Press.

- Celeste Watkins-Hayes, 2019. Remaking a life: How women living with HIV/AIDS confront inequality. Berkeley: University of California Press.

- Elizabeth Freeman, 2010. Time binds: Queer temporalities, queer histories. Durham, N.C.: Duke University Press.

- Shaka McGlotten, 2013. Virtual intimacies: Media, affect, and queer sociality. Albany: State University of New York Press.

- ACT UP/New York Women and AIDS Book Group, 1990. Women, AIDS \& activism. Boston, Mass.: South End Press.

\section{Videos}


To help see the Bashi tape in context, here are two tapes that were made around the same time that are part of a large community of tapes:

- The colour of immunity, produced for the Toronto Living With AIDS (TLWA), 1991: https://aidsactivisthistory.ca/2017/11/27/from-the-videovault-the-colour-of-immunity-1991/

- A clip of mainstream American news coverage of HIV from 19821992: https://www.youtube.com/watch?v=zPO5wausim8

Here are other videos in conversation with the Bebashi tape:

- AIDS in the bario, Frances Negron, 1997

- Life support, Nelson George, 2007

- Nothing without us: The women who will end AIDS, Harriet Hirshorn, 2017

- Unrest, Jennifer Brea, 2017

- We Care, WAVE (Women's AIDS Video Enterprise), 1990

- Women and AIDS, Alexandra Juhasz and Jean Carlomusto, 1987

\section{Editorial history}

Received 14 October 2019; 5 February 2020; accepted 28 August 2020.

Copyright (C) 2020, Alexandra Juhasz and Theodore Kerr. All Rights Reserved.

Watching and talking about AIDS: Analog tapes, digital cultures, and strategies for connection

by Alexandra Juhasz and Theodore Kerr.

First Monday, Volume 25, Number 10 - 5 October 2020

https://journals.uic.edu/ojs/index.php/fm/article/download/10283/9735

doi: https://dx.doi.org/10.5210/fm.v25i10.10283 